\title{
ANTHELMINTIC ACTIVITY OF SUB-FRACTIONS FROM THE N-HEXANE FRACTION OF PICRIA FEL-TERRAE LEAVES ON PHERETIMA POSTHUMA
}

\author{
POPI PATILAYA ${ }^{*}$, DADANG IRFAN HUSORI², LINDA MARHAMA DAULAY² \\ ${ }^{1}$ Department of Biological Pharmacy, Faculty of Pharmacy, Universitas Sumatera Utara, Medan, Indonesia. ${ }^{2}$ Department of Pharmacology, \\ Faculty of Pharmacy, Universitas Sumatera Utara, Medan, Indonesia.Email: popi.patilaya@usu.ac.id
}

Received: 07 March 2018, Revised and Accepted:25 March 2018

\section{ABSTRACT}

Objective: This study was to evaluate the anthelmintic activity of the subfractions (SF) from n-hexane fraction of Picria fel-terrae leaves on Pheretima posthuma.

Methods: The leaves ethanolic extract of $P$. fel-terrae solution was mixed with water in ratio of 7:3. The mixture was fractionated with n-hexane by liquid-liquid extraction. The n-hexane fraction was then separated on silica gel by vacuum liquid chromatography with n-hexane-ethyl acetate and methanol as mobile phases. The filtrates with same chromatogram pattern were combined to produce SF of the plant leaves. The SF at the concentration of $0.1 \%$ was tested on P. posthuma to evaluate its anthelmintic activity. The anthelmintic activity was determined by observing paralysis and death times of the worms. Pyrantel $0.1 \%$ and vehicle were included as positive and negative controls, respectively.

Results: The study showed that n-hexane fraction of $P$. fel-terrae leaves produced 4 SF, namely, SF1, SF2, SF3, and SF4. The earthworms were paralyzed at $123.00,130.33,78.67,74.33$, and 127.33 min when treated with SF1, SF2, SF3, SF4, and pyrantel, respectively. The SF1, SF2, SF3, SF4, and pyrantel also caused the animal death at $156.00,166.67,107.00,101.67$, and $140.00 \mathrm{~min}$, respectively. The animal paralysis and death times by those substances were shorter than negative control effects.

Conclusion: This study suggests that the SF from n-hexane fraction of $P$. fel-terrae leaves has anthelmintic activity on $P$. posthuma. The effects of SF4 are strongest when compared with SF1, SF2, SF3, and pyrantel.

Keywords: Anthelmintic, Picria fel-terrae, Pheretima posthuma, Helminthiasis.

(C) 2018 The Authors. Published by Innovare Academic Sciences Pvt Ltd. This is an open access article under the CC BY license (http://creativecommons. org/licenses/by/4. 0/) DOI: http://dx.doi.org/10.22159/ajpcr.2018.v11s1.26568

\section{INTRODUCTION}

More than 1 billion of the world population is infected by parasitic worms. Helminthiasis cases commonly occur in tropic and subtropic regions, especially Africa, America, and South-East Asia. In Indonesia, helminthiasis also remains a health problem in which more than 4 million people infected are found [1]. In addition, the emergence of resistant worm strains lead to helminthiasis is difficult to eradicate [2,3]. To solve these problems, development of new anthelmintics from medicinal plants is very urgent [4]

Picria fel-terrae has been used to treat helminthiasis by Indonesian people [5]. The leaves ethanolic extract of this plant has anthelmintic activity on Pheretima posthuma Ascaridia galli. The plant extract contains flavonoids, saponins, tannins, glycosides, and steroids/ triterpenoids. However, the active compounds of plant extract that responsible for anthelmintic activities have not been identified, so it is need to be studied [6]. According to Yalavarthi and Thiruvengadarajan, before the isolation of active compounds, studies on fractions or subfractions (SF) from plant extracts could be done to selected the active substance [7]. This work was to study the anthelmintic activity of SF from the n-hexane fraction of $P$. fel-terrae leaves on Pheretima posthuma.

\section{METHODS}

\section{Chemicals}

Sodium chloride, silica gel, $96 \%$ ethanol, n-hexane, ethyl acetate, methanol, sodium carboxymethylcellulose, tween-80, and LiebermanBurchard reagent were purchased from Merck, Germany. Distilled water was purchased from Rudang Jaya, Indonesia, while pyrantel was obtained from Sigma-Aldrich, USA.

\section{Preparation of plant SF}

P. fel-terrae leaves were extracted with $96 \%$ ethanol. The plant extract solution was mixed with water in ratio of 7:3 and then fractionated with n-hexane by liquid-liquid extraction. The n-hexane fraction (19.4 g) was then separated on silica gel by vacuum liquid chromatography with n-hexane-ethyl acetate in ratios of (100:0), (90:10), (80:20), (70:30), $(60: 40),(50: 50),(40: 60),(30: 70),(20: 80),(10: 90)$, and $(0: 100)$ and methanol as mobile phases. Each $250 \mathrm{~mL}$ of filtrate was collected and separated by thin layer chromatography with Lieberman-Burchard as detecting agent. The filtrates with same chromatogram pattern were combined to produce SF of the plant leaves.

\section{Anthelmintic activity testing}

The procedure from Agrahari et al. and Hounzangbe-Adote et al. were adopted in this study with slight modifications $[8,9]$. P. posthuma was acclimated in saline solution for $60 \mathrm{~min}$. The worms were exposed to the plant SF and pyrantel at the concentration of $0.1 \%$. Saline solution containing $\mathrm{Na}-\mathrm{CMC}$ and tween-80 was included as negative control. Anthelmintic activity of these samples was determined by observing paralysis and death times of the worms during the experiment.

\section{RESULTS}

Fig. 1 described the chromatogram patterns of SF from n-hexane fraction of $P$. fel-terrae leaves. The results showed that the plant fraction produced 4 SF, namely, SF1, SF2, SF3, and SF4. The bands with reddish purple and bluish green may indicate the presence of steroids/ triterpenoids compounds.

Table 1 describes the effects of SF from n-hexane fraction of $P$. fel-terrae leaves on $P$. posthuma. The results showed that the SF of the plant caused paralysis and death of the worms. The paralysis time of worms treated by the plant SF was shorter than vehicle effects as well as the 


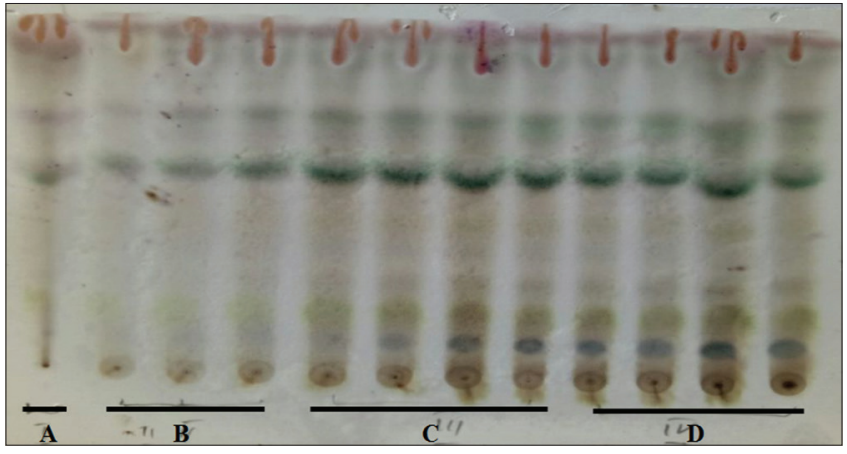

Fig. 1: Chromatogram of subfractions from $n$-hexane fraction of Picria fel-terrae leaves (A) subfraction 1, (B) subfraction 2, (C) subfraction 3, (D) subfraction 4

Table 1: The effects of SF from $\mathrm{n}$-hexane fraction of $P$. fel-terrae leaves on the paralysis and death of $P$. posthuma

\begin{tabular}{lll}
\hline Treatment & Paralysis time* $^{*}$ min) & Death time* $(\mathbf{m i n})$ \\
\hline SF1 & $123.00 \pm 5.29$ & $156.00 \pm 7.55$ \\
SF2 & $130.33 \pm 1.45$ & $166.67 \pm 0.88$ \\
SF3 & $78.67 \pm 0.88$ & $107.00 \pm 1.15$ \\
SF4 & $74.33 \pm 0.67$ & $101.67 \pm 0.33$ \\
Pyrantel $0.1 \%$ & $127.33 \pm 1.45$ & $140.00 \pm 2.65$ \\
Vehicle & $310.33 \pm 2.60$ & $369.33 \pm 2.91$ \\
\hline
\end{tabular}

*The data are presented as mean \pm SE. SF: Subfractions, P. posthuma: Pheretima posthuma, P. fel-terrae: Picria fel-terrae

death time. Statistical analysis also indicated that the anthelmintic effects between samples tested were significantly different $(p<0.05)$. It means that the effects of SF4 are strongest when compared with SF1, $\mathrm{SF} 2, \mathrm{SF} 3$, and pyrantel.

\section{DISCUSSIONS}

Different species of worms such as earthworms, Ascaris, Nippostrongylus, and Heterakis are used to assess the anthelmintic activity of natural products. However, the earthworms have been widely used for the initial study of in vitro anthelmintic activity [10]. According to Sen et al., substances that have anthelmintic activity on the earthworms is also effective against parasitic worms of human [11]. The present study exhibited the anthelmintic activity of SF4 is most potent to $P$. posthuma among the others even than the standard pyrantel. This result indicates that probable active compounds of $P$. fel-terrae leaves may concentrated in this SF. According to Kumarasingha et al., fraction derived from the dichloromethane: methanol extract of the whole plant exhibits anthelmintic activity on Caenorhabditis elegans [12].

This study also revealed that the active plant SF consists of steroids/ triterpenoids compounds. Plant steroids have the ability to afford specific action mainly on muscle, while triterpenoids may inhibit glucose uptake and depletes the glycogen content in worms [13]. Interestingly, the plant SF SF4 is more potent than standard drugs, pyrantel. Pyrantel is nicotinic receptor agonist that produces muscle paralysis of worms due to prolonged activation of the excitatory nicotinic acetylcholine receptors on the body wall muscle [14]. Therefore, further study is needed to isolate the active compounds of $P$. fel-terrae leaves as well as its action mechanisms.

\section{CONCLUSION}

This study suggests that the $\mathrm{SF}$ from n-hexane fraction of $P$. fel-terrae leaves has anthelmintic activity on P. posthuma. The effects of SF4 are strongest when compared with SF1, SF2, SF3, and pyrantel.

\section{ACKNOWLEDGMENT}

We thank the Indonesian Ministry of Research, Technology, and Higher Education for their funding support through Fundamental Research Scheme 2017 with contract number 003/SP2H/LT/DRPM/IV/2017.

\section{REFERENCES}

1. World Health Organization. Media Centre: Soil-Transmitted Helminth Infections; 2014. Available from: http://www.who.int/mediacentre/ factsheets/fs366/en/. [Last accessed on 2017 Apr 10].

2. Graef JD, Claerebout E, dan Geldhof P. Anthelmintic resistance of gastrointestinal cattle nematodes. Vlaams Diergeneeskundig Tijdschrift 2013;82:113-23

3. Vercruysse J, Albonico M, Behnke JM, Kotze AC, Prichard RK, McCarthy JS, et al. Is anthelmintic resistance a concern for the control of human soil-transmitted helminths?. Int J Parasitol Drugs Drug Resist 2013;1:14-27.

4. Yadav P, Singh R. A review on anthelmintic drugs and their future scope. Int J Pharm Pharma Sci 2011;3:17-21.

5. Tinton A. Smart Book of Medicinal Plants. $1^{\text {st }}$ ed. Jakarta: Agromedia Pustaka; 2008

6. Patilaya P, Husori DI. Preliminary study on the anthelmintic activity of the leaf ethanolic extract of Indonesian Curanga fel-terrae (Lour.) merr. Int J Pharm Tech Res 2015;8:347-51.

7. Yalavarthi C, Thiruvengadarajan VS. A review on identification strategy of phyto constituents present in herbal plants. Int J Res Pharm Sci 2013;4:123-40.

8. Agrahari AK, Meher A, Padhan AR, Dash S. Assessment of anthelmintic activity of Jussiaea hyssopifolia G. Don. Asian J Plant Sci Res 2011;1:87-91.

9. Hounzangbe-Adote S, Fouraste I, Moutairou K, Hoste H. In vitro effects of four tropical plants on the activity and development of the parasitic nematode, trichostrongylus colubriformis. J Helminthol 2005;70:29- 33 .

10. Chandrashekhar CH, Latha KP, Vagdevi HM, Vaidya VP. Anthelmintic activity of the crude extracts of Ficus racemosa. Int $\mathrm{J}$ Green Pharm 2008;2:100-3

11. Sen S, De B, Devanna N, Chakraborty R. Anthelmintic and in vitro antioxidant evaluation of fractions of methanol extract of Leea asiatica leaves. Anc Sci Life 2012;31:101-6.

12. Kumarasingha R, Karpe AV, Preston S, Yeo TC, Lim DSL, Tu CL, et al. Metabolic profiling and in vitro assessment of anthelmintic fraction of Picria fel-terrae Lour. Int J Parasitol Drugs Drugs Resist 2016;6:171-8.

13. Doughari JH. Phytochemicals: Extraction Methods, Basic Structures and Mode of Action as Potential Chemotherapeutic Agents. Phytochemicals - A Global Perspective of their Role in Nutrition and Health; 2012. Available from: http://www. intechopen.com/download/pdf/ 32936. [Last accessed 2017 Jul 12].

14. Holden-Dye L, Walker RJ. Anthelmintic drugs. The C. elegans Research Community; 2007. Availble from: http://www.wormbook org. [Last accessed $2017 \mathrm{Jul}$ 12]. 